\title{
An Analysis of the Level of Knowledge on Prevention and Control of Breast Cancer among Female Undergraduates of University of Moratuwa
}

Thushari M. Seneviratne ${ }^{1}$, Suraj Perera ${ }^{2}$ and Sujitha A. Seneviratne ${ }^{3}$

\begin{abstract}
Breast Cancer is the most common form of cancer in Sri Lanka. Cancer is often curable if detected early. This study was conducted to investigate the level of knowledge of female undergraduates on prevention and control of breast cancer. Adopting the survey method, a semi- structured questionnaire was randomly distributed among 732 female undergraduates of three faculties of University of Moratuwa. Results revealed that the majority of the respondents have heard about breast cancer as well as some clinical features of breast cancer but their knowledge on risk factors of breast cancer and detection methods are not sufficient. They are aware about Breast Self-Examination (BSE) as a method of detection of breast cancer. However, majority do not know the technique of performing BSE. Their awareness about Well Woman Clinic is also low. Female undergraduates seek or encounter health related information through television, the Internet and newspapers as well as from medical officers. Majority do not believe the use of social media such as Facebook can be used to educate about breast cancers. Health education is vital in the university setup as undergraduates are future leaders. Regular awareness programmes to educate undergraduate about health aspects is the most preferred method.
\end{abstract}

Keywords: Breast Cancer, Breast Self-Examination (BSE), Menarche, Menopause, Health Literacy, Social Media

\footnotetext{
${ }^{1}$ Senior Assistant Librarian, University of Moratuwa. Email: thushari@lib.mrt.ac.lk

${ }^{2}$ Consultant Community Physician and Primary Care Physician, National Cancer Control Programme, Ministry of Health

${ }^{3}$ Resident Physician, South Colombo Teaching Hospital
} 


\section{Introduction}

"Cancer" is caused when cells in an organ or tissue of the body continue to grow indefinitely without any need. Many cancers spread to other parts of the body and kill the patient (Qalwa, Mohamed \& Eltayb, 2013). Cancer is the second leading cause of death after cardiovascular diseases worldwide. Nearly 10 million people are diagnosed with cancer per year and more than 6 million die due to cancer every year (Qalwa, Mohamed \& Eltayb, 2013). Breast cancer is the most frequent cancer of women worldwide (Radi, 2013). According to the World Health Organization, the occurrence of breast cancer is increasing. Breast cancer rates are increasing in the developed countries as well as developing countries. Nearly 1.7 million new breast cancer cases are diagnosed in 2012 (WCRF International, 2015). Cancer rates are rising among South Asian population and more specifically among South Asian American woman from India, Pakistan and Sri Lanka. (Jafri, 2011 as cited in Qalwa, Mohamed and Eltayb, 2013)

Cancer is an important cause of morbidity and mortality in Sri Lanka. According to the latest cancer registration data, in the year of 2009, a total of 16,888 newly diagnosed cancers were treated at government cancer treatment centres including National Cancer Institute, Maharagama (National Cancer Control Programme, 2015). The age specific standardized cancer incidence rate in the year 1985 was 37.6 per 100,000 population and in the year of 2005, it was 65.7 per 100,000 population showing an increasing trend of cancers in Sri Lanka (National Cancer Control Programme, 2009). In 2009 , recorded rate is 82.6 per 100,000 population showing further increase (National Cancer Control Programme, 2015). Figure 1 presents age standardized death rates related to cancer in Sri Lanka for the period of 2001 to 2009 (National Cancer Control Programme, 2015).

According to cancer incidence data 2009 (National Cancer Control Programme, 2015), cancers in the breast, oral cavity, cervix ovary, oesophagus, trachea, bronchus and lungs, colon and rectum, thyroid gland and prostate gland are among the nine most common cancers in Sri Lanka. Breast cancers is the most common form of cancer in Sri Lanka. Around 2500 new breast cancer patients are detected every year. Of this $98 \%$ are 
females. Breast cancer is often curable if detected early. However, Sri Lanka females are not aware of the state or tend to suffer.

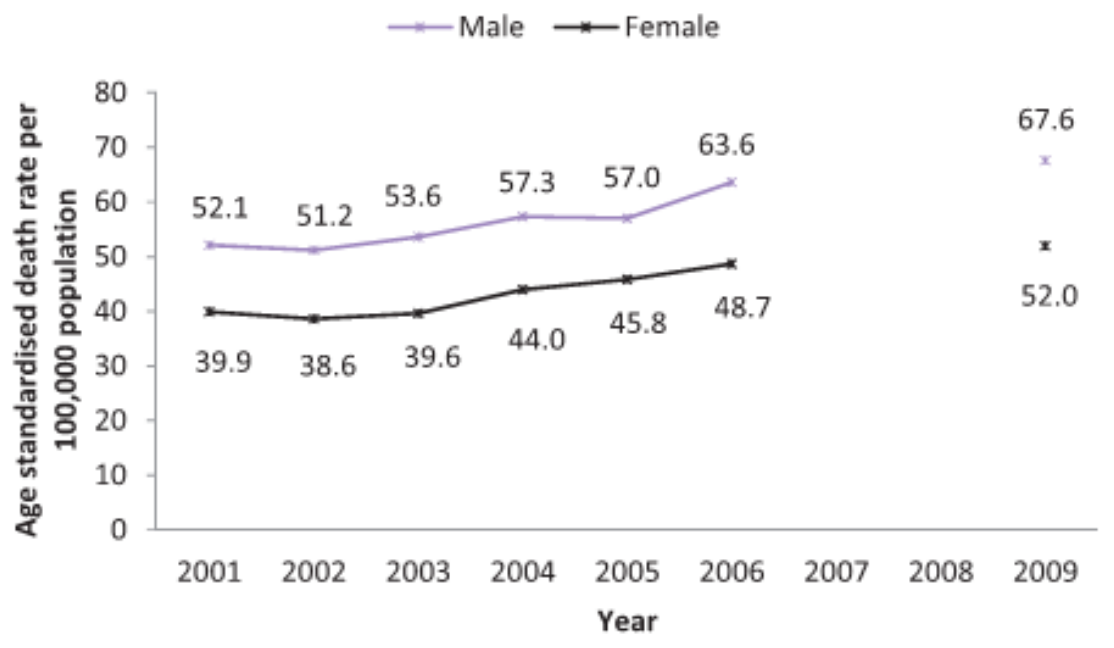

Figure 1: Age standardized death rates in Sri Lanka according to Cancer incidence data, 2009 (Source: National Cancer Control Programme, 2015)

If a female is health literate she has a better opportunity get a knowledge and awareness of risk factors associated and symptoms of breast cancer. In Sri Lankan setup, Well Woman Clinics are established for the purpose and are conducted by a medical officer or public nursing sister.

Health literacy can be explained as one's ability to obtain, process and understand health information and services to enable sound health decision making (Koay, Schofield \& Jefford, 2012). A healthy population is an asset to any country and directly related to the economic growth and development. Health literacy is fundamentally important to maintain a population's health. National survey on emerging issues among adolescents recognized health literacy as a life skill since adolescence has recently gained recognition as a critical phase of life (United Nations Children's Fund - UNICEF, 2004). On the other hand, health literacy as a life skill will have a greater impact on adult health.

Undergraduates just passed adolescence will be future leaders of the society and female undergraduates will be future mothers in the community. They 
will take the leadership at their working places and in the society. In addition female undergraduates will be future mothers in the community. Therefore in this context female undergraduates should be knowledgeable in health related matters.

Since health literacy is fundamentally important to maintaining a population's health, this study will be useful to identify the health literacy level with respect to prevention and control of breast cancers. To add up, most undergraduates of University of Moratuwa have followed nonbiological streams in their tertiary education. Therefore measuring health literacy will alarm stakeholders. Library collections could be upgraded to cater their health literacy needs.

\section{Objectives}

The study aimed to satisfy following specific objectives

- To Analyze the level of knowledge on breast cancer

- To Analyze the level of knowledge on available screening techniques for breast cancer

- To Analyze awareness about the health information sources

- To assess the need for health education for undergraduate

\section{Literature Review}

Vast amount of literature is available on knowledge and awareness of cancer especially breast cancer among females belonging to various age groups, educational levels as well socio economic levels etc. Multivariate analysis conducted by Al-Dubai et al. (2011) has revealed significant predictors of breast cancer knowledge were age, race, marital status, level of education, occupation, family size and family history of other breast cancers. Hence, it is important to review different types of studies, methodologies etc.

To determine the extent of knowledge and preventive measures of cancer Qalwa, Mohamed \& Eltayb (2013) carried out a descriptive research among 277 non-medical university students residing in El-Khartoum state in Sudan; Sahar Mahmoud Radi conducted a similar study among 200 Saudi females aged 20 and older living in Jeddah in 2013; Hardi, Hassali, Shafie and 
Awaisu (2010) conducted a study among 200 female undergraduates belongs to 10 faculties of Universiti Sains Malasia. Al-Dubai et al. (2011) carried out a cross sectional study among 250 Malaysian women aged 18 to 29 years in Shah Alam; Montazeri et al. (2008) carried out a population-based survey in Tehran among 1402 women with a mean age of 43.4 years; Sathian et al. (2014) evaluated knowledge about among female residents of Pokhara valley, Nepal.

Qalwa, Mohamed \& Eltayb (2013) found out most of the non-medical students are aware of types of cancer, risk factors and warning signs of cancer. Sahar Mahmoud Radi (2013) revealed majority of Saudi females were aware of breast lump as a warning sign of breast cancer and have heard about Breast Self-Examination. However, $47.5 \%$ knew how to perform BSE. On the contrary, majority of female undergraduates of Universiti Sains Malasia were aware of breast self-examination and clinical breast examination also had a positive attitude towards outcomes of breast cancer treatments (Hardi, Hassali, Shafie and Awaisu, 2010) However, Hardi, Hassali, Shafie and Awaisu (2010) revealed that female undergraduates had inadequate knowledge of breast cancer and had a mean total knowledge score of $60.7 \%$. It was also recorded that Indian students of Universiti Sains Malasia had significantly less knowledge than Chinese and Malay counterparts. Dubai et al. (2011) concluded that majority of Malasian women aged 18 to 29 years in Shah Alam did not know about signs and symptoms of breast cancer and many of its risk factors. Montazeri et al. (2008) and Sathian et al. (2014) revealed awareness of the procedure to perform BSE is very low. Researchers have emphasized the importance of raising awareness about the breast cancer in spite of age, race, educational level, socioeconomic background etc.

Since promotion of breast cancer awareness programmes in Sri Lanka has not widely targeted school children, Ranasinghe and fellow researchers conducted a school based study among 859 adolescent girls in the Colombo District of Sri Lanka in 2013. The study aimed to find out knowledge, attitudes and practices regarding breast cancer with reference to screening, services available, breast self-examination, and sources of information. History of breast lump', 'family history of breast cancer' and 'exposure to 
irradiation' have been identified as risk factors for breast cancer but awareness of other warning signs was poor among students. Only $35.6 \%$ of the respondents have identified mammogram as an effective screening method. One third of the respondents were unaware of symptoms, diagnostics and treatment of breast cancer. Out of 859 participants, 17.1\% knew how to perform breast self-examination and only $9.4 \%$ were aware of currently available breast cancer screening services. Researchers also revealed that knowledge was significantly better among students who had a relative with breast cancer. They also highlighted the need for awareness programmes.

\section{Research Methods}

A cross sectional survey was conducted from October 2014 to May 2015 at University of Moratuwa. Five batches (2008 to 2012 batches) of female undergraduates of Faculty of Engineering, Faculty of Architecture and Faculty of Information Technology of University of Moratuwa were the research population. There were 2054 female undergraduates in the five batches in all three faculties. All available female students at the University were invited to participate to this study. Students who were available during data collection and students who were willing to participate for the study were included. Students who were on industrial training and other outside activities were not included.

\section{Research Instrument}

After reviewing the related literature, a semi-structured questionnaire consisted of 50 questions was developed as the research instrument. Questionnaire was divided to 4 main parts namely socio demographic data, knowledge on breast cancer, knowledge on screening of breast cancer and information seeking behaviour.

\section{Data Collection and Data Analysis}

Informed consent from each respondent was obtained prior to the data collection. Majority of the students responded to the questionnaire in a classroom setting. Data was analyzed for descriptive statistics using SPSS. 


\section{Results}

\section{Profile of the Respondents}

Demographic details of the sample are presented in following tables

Table 1: Faculty-wise and Academic year-wise distribution of the respondents

\begin{tabular}{lc|lc}
\hline \multicolumn{1}{c|}{ Faculty } & No. of Students & \multicolumn{1}{c}{ Academic Year } & No. of Students \\
\hline $\begin{array}{l}\text { Faculty of } \\
\text { Architecture }\end{array}$ & $289(39.5 \%)$ & First Year & $351(48.0 \%)$ \\
$\begin{array}{l}\text { Faculty of } \\
\text { Engineering }\end{array}$ & $246(33.6 \%)$ & Second Year & $218(29.8 \%)$ \\
$\begin{array}{l}\text { Faculty of } \\
\text { Information } \\
\text { Technology }\end{array}$ & $197(26.9 \%)$ & Third Year & $62(8.5 \%)$ \\
& & & \\
\multicolumn{1}{c}{ Total } & $\mathbf{7 3 2}$ & Fourth Year & $72(9.8 \%)$ \\
\hline
\end{tabular}

Table 2: District from which undergraduates entered for the university

\begin{tabular}{|l|c|l|c|}
\hline \multicolumn{1}{|c|}{ District } & $\begin{array}{c}\text { No of Students } \\
\text { \& their } \\
\text { percentage }\end{array}$ & \multicolumn{1}{|c|}{ District } & $\begin{array}{c}\text { No of Students } \\
\text { \& their } \\
\text { percentage }\end{array}$ \\
\hline Ampara & $14(1.9 \%)$ & Kilinochchi & $4(0.5 \%)$ \\
\hline Anuradhapura & $18(2.5 \%)$ & Kurunagala & $47(6.4 \%)$ \\
\hline Badulla & $22(3.0 \%)$ & Mannar & $7(1.0 \%)$ \\
\hline Batticaloa & $12(1.6 \%)$ & Matale & $9(1.2 \%)$ \\
\hline Colombo & $136(18.6 \%)$ & Matara & $67(9.2 \%)$ \\
\hline Galle & $65(8.9 \%)$ & Monaragala & $7(1.0 \%)$ \\
\hline Gampaha & $63(8.6 \%)$ & Mulathivu & $5(0.7 \%)$ \\
\hline Hambantota & $25(3.4 \%)$ & Nuwara-Eliya & $14(1.9 \%)$ \\
\hline Jaffna & $25(3.4 \%)$ & Polonnaruwa & $9(1.2 \%)$ \\
\hline Kalutara & $32(4.4 \%)$ & Puttlam & $11(1.5 \%)$ \\
\hline Kandy & $47(6.4 \%)$ & Rathnapura & $39(5.3 \%)$ \\
\hline Kegalle & $34(4.6 \%)$ & Trincomalee & $5(0.7 \%)$ \\
\hline Vavuniya & $6(0.8 \%)$ & \multicolumn{2}{|l}{} \\
\hline
\end{tabular}


Table 3: Characteristics of the sample

\section{Ethnicity}

$\begin{array}{lrr}\text { Sinhala } & 624 & 85.4 \\ \text { Tamil } & 76 & 10.4 \\ \text { Muslim/Moor } & 31 & 4.2\end{array}$

\section{$\underline{\text { Religion }}$}

Buddhism

$592 \quad 81.0$

Islam

$31 \quad 4.2$

Christianity

$\begin{array}{ll}44 & 6.0\end{array}$

Hinduism

$62 \quad 8.5$

Others

2.3

\section{G.C.E. (Advanced Level) Stream}

$\begin{array}{lrr}\text { Mathematics } & 304 & 41.5 \\ \text { Biology } & 87 & 11.9 \\ \text { Commerce } & 70 & 9.6 \\ \text { Arts } & 271 & 37.0\end{array}$

Followed Health as a Subject

$\begin{array}{lrr}\text { Yes } & 546 & 99.9 \\ \text { No } & 3 & 0.3\end{array}$

\section{Father's Education}

Grade 1-5

Grade 6-9

Grade 10-11

Grade 12-13

Degree/Diploma/Post Graduate Degree

Others

$\begin{array}{rl}19 & 2.6 \\ 23 & 3.1 \\ 109 & 14.9 \\ 358 & 48.9 \\ 206 & 28.1 \\ 4 & 0.5\end{array}$

\section{Mother's Education}

Grade 1-5

Grade 6-9

Grade 10-11

Grade 12-13

Degree/Diploma/Post Graduate Degree

Others

$\begin{array}{ll}7 & 1 \\ 8 & 1.1 \\ 73 & 10.1 \\ 301 & 41.6 \\ 323 & 44.6 \\ 12 & 1.7\end{array}$




\section{Knowledge on Breast Cancer}

Out of 732 respondents, 708 (97.1\%) have heard about breast cancer in Sri Lanka; $5.5 \%$ of the respondents believed breast cancer is a rare disease among females in Sri Lanka; 33.7\% of the respondents were in the opinion of breast cancer is a relatively common disease; $15.9 \%$ of the respondents thought it is the second commonest cancer and $32.1 \%$ felt breast is the commonest cancer in Sri Lanka. To add up, $68.2 \%$ of the respondents are having the idea that breast cancer can be cured if diagnosed early. Out of 732 respondents $11(1.5 \%)$ students had a personal history of breast cancer and $46(6.3 \%)$ had a family history of breast cancer. It was noted that 451 (61.6\%) students had known some person with a breast cancer. Majority of the respondents $(66.1 \%)$ stated age range - 35 years to 64 years - as the age group which breast cancer is commonest in Sri Lanka. Knowledge of the respondents regarding the risk factors associated with breast cancer was found out using statements presented in Table 4. Based on the responses their knowledge on risk factors were categorized and presented in Figure 2.

Table 4: Knowledge about breast cancer

\begin{tabular}{|l|}
\hline \multicolumn{1}{|c|}{ Statement } \\
\hline 1. Fat women are at a higher risk for getting breast cancer \\
2. Prolonged breast feeding is a risk factor for breast cancer \\
3. Women taking oral contraceptives or hormone replacement therapy more than \\
5 years are at a higher risk of getting breast cancer \\
4.Women who attained menarche (first mensus) before 11 years are at a higher \\
risk for breast cancer \\
5. Having more children is a risk factor for breast cancer \\
6. Women who had menopause after 55 years are at a higher risk for breast \\
cancer \\
7. Not having children is a risk factor for breast cancer \\
8. Breast cancer can be inherited \\
9.Women who had first child birth at or after 35 year are at a higher risk for \\
getting breast cancer \\
10.Women who have family history of ovarian cancer are at a higher risk for \\
getting breast cancer \\
11.Women who have past history of breast cancer are at a higher risk for getting \\
breast cancer
\end{tabular}




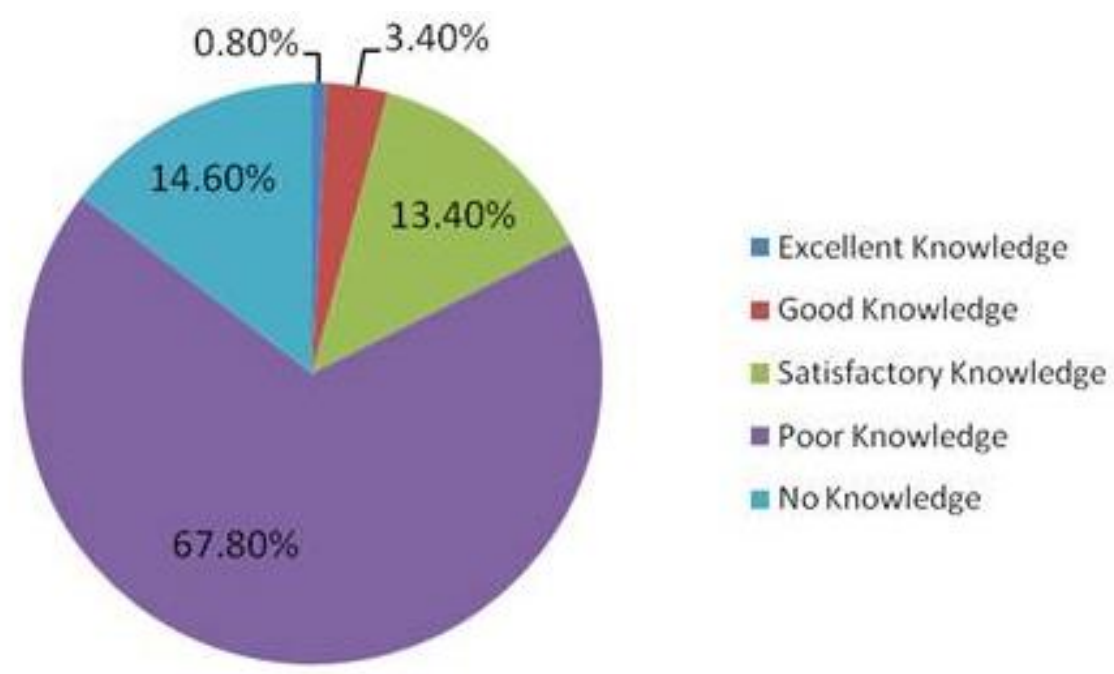

Figure 2: Knowledge about breast cancer

Knowledge of the respondents about the person who performs the clinical breast examination is depicted in Table 5. Students' awareness with respect the above fact is also low; $31.8 \%$ of the respondents did not have any idea about the person who performs the clinical breast examination.

Respondents' awareness and knowledge about clinical features of breast cancer is also presented in Table 6. According to the data, majority of the respondents are aware about some clinical features of breast cancer such as painless lump in the breast, change in shape of the breast or volume, changes in the skin of the breast etc.

Table 5: Knowledge about the person who do the clinical breast examination

\begin{tabular}{|c|c|}
\hline Person & \% responded \\
\hline Surgeon & 33.6 \\
\hline Doctor & 14.3 \\
\hline Public Health Nursing Sister & 13.8 \\
\hline Nursing Officer & 3.4 \\
\hline Public Health Midwife & 13.5 \\
\hline I do not know & 31.8 \\
\hline Others & 1.1 \\
\hline
\end{tabular}


Table 6: Common clinical features of breast cancer

\begin{tabular}{|l|l|l|l|}
\hline \multicolumn{1}{|c|}{ Clinical Feature } & \multicolumn{1}{|c|}{ Yes } & \multicolumn{1}{|c|}{ No } & \multicolumn{1}{|c|}{$\begin{array}{c}\text { Do not } \\
\text { Know }\end{array}$} \\
\hline 1. Painful lump in the breast & $54.1 \%$ & $20.1 \%$ & $25.8 \%$ \\
\hline 2. Painless lump in the breast & $61.1 \%$ & $12.9 \%$ & $26.0 \%$ \\
\hline 3. Lump in the armpit & $31.1 \%$ & $8.8 \%$ & $61.1 \%$ \\
\hline $\begin{array}{l}\text { 4. Change in shape of breast shape or } \\
\text { volume }\end{array}$ & $57.9 \%$ & $7.8 \%$ & $34.3 \%$ \\
\hline 5. Swelling of breast & $41.0 \%$ & $6.8 \%$ & $52.3 \%$ \\
\hline 6. Changes in the skin of the breast & $54.0 \%$ & $6.4 \%$ & $39.6 \%$ \\
\hline 7. Change in the position of the nipple & $35.7 \%$ & $11.7 \%$ & $52.6 \%$ \\
\hline 8. Nipple discharge & $32.9 \%$ & $5.9 \%$ & $61.2 \%$ \\
\hline
\end{tabular}

\section{Knowledge on Screening of Breast Cancer}

Breast Self-Examination is widely used to detect breast cancers. Out of 732 respondents, $68 \%$ have heard about BSE and $69.1 \%$ stated that BSE help in early detection of breast cancers. 'At the age of twenty years' has been listed as appropriate time to start breast cancer by $68.2 \%$ of the respondents and $23.4 \%$ do not have knowledge about the fact. Majority of respondents $(69.8 \%)$ have stated frequency of conducting BSE is once a month and $26.5 \%$ have stated it is once a week. Majority of the respondents $(57.7 \%)$ also not aware about time of conducting BSE and $25.3 \%$ stated 'any time'; $2.8 \%$ stated 'before menstruation'; $2.3 \%$ stated 'during menstruation. etc. There can be barriers to BSE. Respondent listed the following reasons (Table 7) as the barriers to BSE:

Table 7: Barriers to Breast Self-Examination

\begin{tabular}{|l|l|}
\hline \multicolumn{1}{|c|}{ Barrier } & \% \\
\hline Lack of time & $7.9 \%$ \\
\hline Fear of finding some abnormality & $4.2 \%$ \\
\hline Not aware about breast self-examination & $17.8 \%$ \\
\hline Don't know the proper way to do it & $4.2 \%$ \\
\hline Not at risk hence not required to do so & $1.1 \%$ \\
\hline Lack of privacy & $5.8 \%$ \\
\hline
\end{tabular}


Only $19.9 \%$ (134) of the respondents are aware about the technique of conducting BSE and $82 \%$ (91) have learnt the technique from non-medical personnel. However, only 15 students could clearly explained the main steps in BSE. Female students' awareness on methods of early detection of breast cancer was also investigated and results could be found in Table 8 .

Table 8: Methods of early detection of breast cancer

\begin{tabular}{|l|l|l|l|}
\hline \multicolumn{1}{|c|}{ Method } & \multicolumn{1}{|c|}{ Yes } & \multicolumn{1}{|c|}{ No } & \multicolumn{1}{c|}{$\begin{array}{c}\text { Do not } \\
\text { know }\end{array}$} \\
\hline 1. Ultra sound scan & $47 \%$ & $8.7 \%$ & $44.3 \%$ \\
\hline 2. Mammography & $33.1 \%$ & $4.4 \%$ & $62.5 \%$ \\
\hline 3. Full blood count & $45.2 \%$ & $16 \%$ & $38.8 \%$ \\
\hline 4.Breast self-examinations & $80.6 \%$ & $2 \%$ & $17.4 \%$ \\
\hline 5. X-ray & $45.7 \%$ & $12.7 \%$ & $31.6 \%$ \\
\hline 6. Clinical breast examination & $80.2 \%$ & $1.4 \%$ & $18.4 \%$ \\
\hline 7. Biopsy & $18.3 \%$ & $5.4 \%$ & $76.3 \%$ \\
\hline
\end{tabular}

Majority of the respondents identified screening methods for early detection of this fatal disease as mammography, clinical breast examination and breast self-examination. Further, majority of the respondents (87.1\%) are aware that above facilities are available in Sri Lanka. However, only $29.1 \%$ of the respondents have heard about Well Woman Clinic.

\section{Health Literacy and information sources}

Although health literacy is not a new concept, 138 respondents $(20.1 \%)$ have heard about it. Only 25 students have clearly described it. However, respondents used the sources mentioned in Table 9 to get information about health related topics. According to the Table 9, four frequently used information sources which used by more than one third of the respondents are television, Internet, medical officers and newspapers. Health talk at university, billboards, nursing staff and midwives are least used information sources with respect to health aspects. 
Table 9: Information sources used to get information about health

\begin{tabular}{|l|l|l|l|l|}
\hline \multicolumn{1}{|c|}{ Source } & Frequently & Sometimes & Rarely & Never \\
\hline From a Doctor & $39.1 \%$ & $34.7 \%$ & $19.0 \%$ & $7.2 \%$ \\
\hline $\begin{array}{l}\text { From Public a Health Nursing } \\
\text { Sister }\end{array}$ & $14.0 \%$ & $22.9 \%$ & $26.6 \%$ & $36.5 \%$ \\
\hline From a Nursing Officer & $9.9 \%$ & $23.5 \%$ & $27.3 \%$ & $39.3 \%$ \\
\hline From a Public Health Midwife & $13.8 \%$ & $22.9 \%$ & $23.7 \%$ & $39.6 \%$ \\
\hline From a friend/neighbour/relative & $28.6 \%$ & $44.3 \%$ & $18.2 \%$ & $9.2 \%$ \\
\hline From Television & $41.9 \%$ & $42.4 \%$ & $13.2 \%$ & $2.5 \%$ \\
\hline From radio & $20.9 \%$ & $39.2 \%$ & $24.8 \%$ & $15.1 \%$ \\
\hline From books & $24.9 \%$ & $42.9 \%$ & $24.5 \%$ & $7.7 \%$ \\
\hline From Magazines & $27.9 \%$ & $46.4 \%$ & $17.8 \%$ & $7.9 \%$ \\
\hline From newsletters & $19,5 \%$ & $39.0 \%$ & $25.6 \%$ & $16 \%$ \\
\hline From Posters / Banners & $18.1 \%$ & $44.0 \%$ & $26.1 \%$ & $11.9 \%$ \\
\hline From newspapers & $37.2 \%$ & $44.0 \%$ & $15.2 \%$ & $3.6 \%$ \\
\hline From Internet & $41.7 \%$ & $34.2 \%$ & $14.9 \%$ & $9.1 \%$ \\
\hline Exhibitions & $7.9 \%$ & $33.4 \%$ & $40.2 \%$ & $16.6 \%$ \\
\hline Bill boards & $4.8 \%$ & $21.7 \%$ & $34.5 \%$ & $39.1 \%$ \\
\hline Health talk at the university & $4.4 \%$ & $23.8 \%$ & $29.9 \%$ & $41.9 \%$ \\
\hline
\end{tabular}

Furthermore, $17.7 \%$ and $49.6 \%$ of the respondents strongly agree and agree to the fact that Sri Lankan mass media is actively involved in educating about breast cancers. Television programmes named "Nugasevana" and "Meet your Doctor" are popular among respondents."Sirikatha" and "Lankadeepaya" are listed as popular newspapers and Sooriyan FM has been listed as a popular radio channel. Though Internet has been listed as a frequent source of information with related to health aspects, the fact social media such as Facebook can be used to educate about breast cancers is questionable; only $9.3 \%$ strongly agree and $28.4 \%$ agree with the fact. University library has been used by $6.9 \%$ of the respondents to search health related information. Finally, respondents' opinion on health education is summarized in Table 10.

Though $41.4 \%$ of the female undergraduates participated have many burning issues in the university than health, majority of the female undergraduates accepted the fact that health education is vital in the university setup as undergraduates are future leaders. Regular awareness programmes to educate 
undergraduate about health aspects is also expected by $76.3 \%$ of the respondents. Nearly $63 \%$ of the respondents like to have a personal collection on health aspects. However, 79.1\% believe Internet provides latest information on health aspects.

Table 10: Need of health education

\begin{tabular}{|l|c|c|c|}
\hline \multicolumn{1}{|c|}{ Statement } & Agree & Disagree & No Opinion \\
\hline $\begin{array}{l}\text { 1. University Library does not have items on } \\
\text { health aspects }\end{array}$ & $9.3 \%$ & $37.0 \%$ & $53.7 \%$ \\
\hline $\begin{array}{l}\text { 2. University Library have outdated items on } \\
\text { health aspects }\end{array}$ & $10.4 \%$ & $20.8 \%$ & $68.8 \%$ \\
\hline $\begin{array}{l}\text { 3. Being a University Library devoted to } \\
\text { technology, it should not have items on } \\
\text { health aspects }\end{array}$ & $12.6 \%$ & $47.3 \%$ & $40.1 \%$ \\
\hline $\begin{array}{l}\text { 4. I wish to have a personal collection on } \\
\text { health aspects }\end{array}$ & $62.7 \%$ & $10.5 \%$ & $26.8 \%$ \\
\hline $\begin{array}{l}\text { 5. Internet provides the latest information on } \\
\text { health aspects }\end{array}$ & $79.1 \%$ & $7.7 \%$ & $13.2 \%$ \\
\hline $\begin{array}{l}\text { 6. University should conduct optional } \\
\text { modules on health aspects }\end{array}$ & $68.9 \%$ & $7.6 \%$ & $23.5 \%$ \\
\hline $\begin{array}{l}\text { 7. There should be regular awareness } \\
\text { programmes to educate undergraduates } \\
\text { about health aspects }\end{array}$ & $76.3 \%$ & $7.1 \%$ & $16.6 \%$ \\
\hline $\begin{array}{l}\text { 8. As an undergraduate I should not worry } \\
\text { about health aspects at this age. }\end{array}$ & $6.8 \%$ & $80.0 \%$ & $6.8 \%$ \\
\hline $\begin{array}{l}\text { 9. There are many burning issues among } \\
\text { university students other than health. }\end{array}$ & $41.4 \%$ & $26.4 \%$ & $32.2 \%$ \\
\hline $\begin{array}{l}\text { 10. Health education is vital in the university } \\
\text { setup as undergraduates are the future } \\
\text { leaders. }\end{array}$ & $76.1 \%$ & $4.3 \%$ & $19.6 \%$ \\
\hline
\end{tabular}

\section{Conclusion}

The study investigated the level of knowledge of architectural, engineering and information technology female undergraduates on prevention and control of breast cancers. The findings of this study, emphasize the need of improving the status of health literacy of female undergraduates. Qalwa et al. (2000); Al-Dubai et al. (2011); Mohamed and Eltayb (2013); Ranasinghe et 
al. (2013) and Radi (2013) also highlighted the need for improving awareness on breast cancer among females.

Majority of the respondents have heard about breast cancer as well as some clinical features of breast cancer. However their knowledge on symptoms and detection methods is not sufficient. Though they are aware about Breast Self-Examination (BSE) as a method of detection, majority of the respondents do not know the technique of performing BSE. Their awareness about Well Woman Clinic is also low.

Female undergraduates seek or encounter health related information through television, Internet and newspapers as well as from medical officers. However, majority of the respondents do not believe, the use of social media such as Facebook can be used to educate about breast cancers.

University library has been used by $6.9 \%$ of the respondents to search health related information. Further, books and magazines are not frequently searched to find health related information. Hence, building health related library collections in the university library could not be taken as a measure of improving health literacy. However, respondents agree with the fact health education is vital in the university setup as undergraduates are future leaders. Conducting regular awareness programmes to educate undergraduate about health aspects is vital.

\section{Acknowledgement}

Authors would like to acknowledge the Senate Research Committee of University of Moratuwa for providing financial assistance for this research. Further, authors wish to thank academic staff members who helped in data collection. Support of Library staff members is also appreciated. Finally, authors would like to acknowledge the assistance provided by Miss Chamathka and Miss Kavindhya in data entering.

\section{References}

Al-Dubai, S. A. R., Qureshi, A. M., Saif-Ali, Riyadh, Ganasegeran, K. Alwan, M. R. \& Hadi, J.I.S. (2011). Awareness and knowledge of 
breast cancer and mammography among group of Malasian women in Shah Alam. Asia Pacific Journal of Cancer Prevention, 12(10), 2531-2538.

Hadi, M. A., Hassali, M. A., Shafie, A. A. \& Awaisu, A. (2010). Evaluation of breast cancer awareness among female university students in Malaysia. Pharmacy Practice (Internet), 8(1), 29-34. Retrieved from http://www.pharmacypractice.org

Koay, K., Schofield, P., \& Jefford, M. (2012). Importance of health literacy in oncology. Asia-Pacific Journal of Clinical Oncology, 8, 14-23.

National Cancer Control Programme. (2009). Cancer incidence data: Sri Lanka 2001- 2005. Colombo, Sri Lanka: National Cancer Control Programme.

National Cancer Control Programme. (2015). Cancer incidence data: Sri Lanka 2009. Colombo, Sri Lanka: National Cancer Control Programme.

Qalwa, S. H. A., Mohamed, M. A. \& Eltayb, R. A. M. (2013). Cancer awareness among non-medical university students in Sudan. International Journal of $\quad$ Advanced Research, 1(8), 93-110.

Radi, S. M. (2013). Breast cancer awareness among Saudi females in Jeddah. Asian Pacific Journal of Cancer Prevention. 14, 4307-4312. Ranasinghe, H. M., Ranasinghe, N., Rodrigo, C., Seneviratne, R. de A. \& Rajapakse, S. (2013). Awareness of breast cancer among adolescent girls in Colombo, Sri Lanka: a school based study. BMC Public Health, 20(13), 1209. doi: $\quad$ 10.1186/1471-2458-131209.

Sathian, B., Nagaraja S. B., Banerjee I, Sreedharan J, De A., Roy B., Rajesh E., ... Menezes R. G. (2014). Awareness of breast cancer warning signs and screening methods among female residents of Pokhara valley, Nepal. Asian Pacific Journal of Cancer Prevention, 15(11), 4723-4726.

School \& Adolescent Health Unit. Family Health Bureau (2013). National strategic plan adolescent health (2013-2017). Colombo, Sri Lanka : Ministry of Health.

UNICEF (2004). National survey on emerging issues among adolescents in Sri Lanka. Colombo 3, Sri Lanka: United Nations Children's Fund.

World Cancer Research Fund International (2015). Breast cancer statistics. Retrieved from http://www.wcrf.org/int/cancer-facts-figures/dataspecific-cancers/breast-cancer-statistics. 